\title{
Knowledge, Themes, and Perspectives
}

\author{
Marvin L. Birnbaum, MD, PhD
}

Keywords: disaster medicine; editors; emergency medicine; knowledge; perceptions; science; scope; themes

\author{
Abbreviations: \\ PDM = Prehospital and Disaster Medi- \\ cine
}

They that think they know everytbing, know notbing.

English Proverb

This issue marks the initiation of an expanded mechanism to meet the mission of Prehospital and Disaster Medicine (PDM) - the publication of Theme Issues. Henceforth, theme issues will be provided at regular intervals in the publication schedule of PDM. Theme issues are a natural evolution in the development of the science of Disaster and Emergency Medicine. The concept follows the example begun by Dr. Lundberg, former editor of the Journal of the American Medical Association (JAMA).

As has become increasingly apparent during my 11 years as Editor of PDM, both Disaster and Emergency Medicine require a broader base of knowledge than do most medical specialties. For example, Disaster Medicine not only incorporates major aspects of all of the medical specialties, but also requires knowledge of several non-medical disciplines as well. This has become increasingly evident particularly with the development of the Guidelines for Evaluation and Research as outlined in the previous publication of the Executive Summary. In Disaster Medicine, we interface with all of the basic societal functions provided in this summary. Given the breadth of knowledge required, it is not possible for any of us to be able to be aware of all that is published in all of these areas that comprise our discipline and of those with which we must interface. Nowhere in medicine are the lines between disciplines so blurred. No one of us is capable of acquiring and digesting all there is to know about all of the aspects of the expanse of disciplines that constitute Disaster and Emergency Medicine.
Theme issues are designed to augment and update our overall knowledge base and perspectives in relation to the area being addressed in the theme. They are designed to accumulate the thinking of experts in a specific aspect of Disaster and Emergency Medicine. It is the mission of each contributor to a theme issue to synthesize all that $s /$ he knows in respect to the theme and to put it into a form that will assist us in expanding our knowledge base in a way that may be useful to our practice. It is the job of each author to bring to us, her/his perspectives that are a result of their ability to interpret their own literature from a perceptions that we cannot be expected to possess.

Guest editors known to be expert in the area to be addressed by a theme issue are chosen by the Editor to shepherd each theme issue. Each Guest Editor accepts the responsibility for identifying experts to address specific aspects of the theme, and to guide the authors to assure that their respective contributions address the theme being addressed in a manner that will be helpful to those of us practicing and thinking about the development of Disaster and Emergency Medicine.

The themes to be addressed in Prehospital and Disaster Medicine are selected by the Editor and the Editorial Board based on input from our readers and the mission of the sponsoring organizations as being most relevant to expanding the perspectives of our readers and in the development of our new and expansive discipline. Based on the assigned topic and discussions with the Editor, the Guest Editors then recruit experts in each specific area to share her/his expertise with us.

The Guest Editors for the current issue, Kimberley I. Shoaf and Steven Rottman, were the organizers of the 
Congress on the Public Health Aspects of Disasters conducted at UCLA during the spring of 1999. They invited each of the speakers to present material that exemplifies the role of Public Health in Disasters. Both of the Guest Editors are faculty in the Center for Public Health and Disaster Relief, University of California-Los Angeles. The Guest Editors have provided us with an introduction to the contents of the issue that highlights the important aspects of each of the contributions. They have assembled a fine theme issue, and I believe the information provided will enlarge our knowledge base, and the issue will serve to emphasize the concepts expressed by Dr. Leus in the editorial that follows. Disaster Medicine is public health and must utilize public health techniques in the evaluation of the interventions applied in the practice of Disaster Medicine.

It is my belief that future theme issues will serve to further our knowledge and expand our perspectives in areas in which we are expected to have a broad base of knowledge. Future themes and their respective Guest Editors include: Terrorism (Michael Moles, Hong Kong, July 2001); Complex Emergencies (Fred (Skip) Burkle, Johns Hopkins University, Baltimore, Maryland, January 2002); Psychosocial Aspects of Disasters, (Gloria Leon, University of Minnesota, July 2002); and
International Law as it relates to Disaster Medicine (Jean Marie Fonrouge, Paris). In addition, the full text of the Guidelines for Evaluation and Research in Disasters will be published within the next year.

Lastly, I wish to call your attention to the comprehensive editorial that follows this Editor's Corner. This editorial is based on the keynote address provided for the 5th Asia-Pacific Conference on Disaster Medicine by Dr. Xavier Leus, Director of the Department of Emergency and Humanitarian Action (DEHA) of the World Health Organization (WHO). Dr. Leus clearly defines the importance of Public Health and its techniques in the promulgation of Disaster Medicine, and raises other important issues related to the apparent lack of progress in our developing science. He forces us to look over our shoulder at what we have known, puts recent developments into perspective, and charges us to push forward in the conduct of evaluations AND the application of the findings that result from such research into producing changes. Pay close attention to the issues he raises. And, let us address these issues during the 12th World Congress for Disaster and Emergency Medicine in May 2001.

Knowledge unused is like a torch in the hand of a blind man. Indian (Kashmiri) Proverb

\section{Reference}

1. Sundnes KO, Birnbaum ML: Health disaster management: Guidelines for evaluation and research in the Utstein style: Executive summary. Prebosp Disast Med 1999; 14:43-52. 